
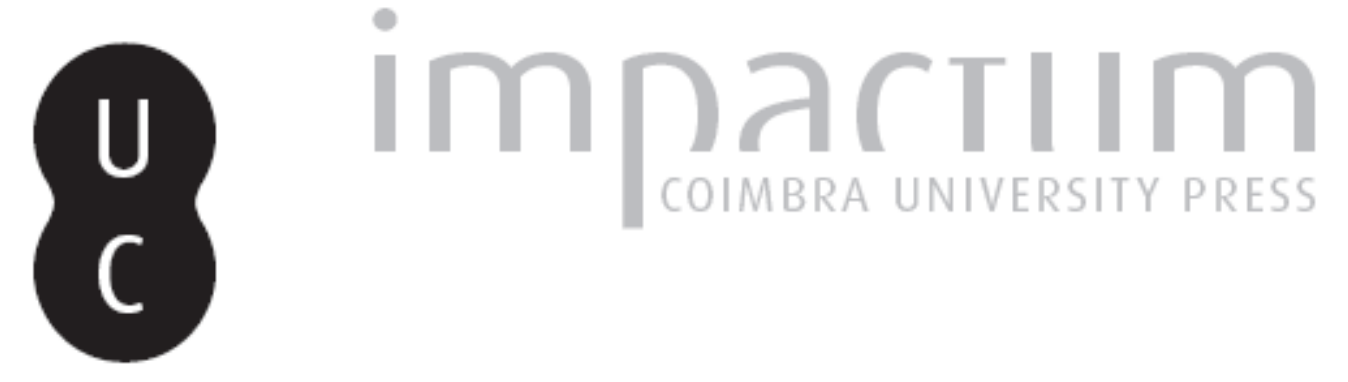

\title{
Turismo na Serra da Estrela: planeamento da atividade turística e desenvolvimento
}

Autor(es): $\quad$ Costa, Carlos; Santos, Norberto

Publicado por: Imprensa da Universidade de Coimbra

URL persistente:

URI:http://hdl.handle.net/10316.2/40771

DOI:

DOI:https://doi.org/10.14195/0871-1623_35_2

Accessed : $\quad$ 26-Apr-2023 13:55:26

A navegação consulta e descarregamento dos títulos inseridos nas Bibliotecas Digitais UC Digitalis, UC Pombalina e UC Impactum, pressupõem a aceitação plena e sem reservas dos Termos e Condições de Uso destas Bibliotecas Digitais, disponíveis em https://digitalis.uc.pt/pt-pt/termos.

Conforme exposto nos referidos Termos e Condições de Uso, o descarregamento de títulos de acesso restrito requer uma licença válida de autorização devendo o utilizador aceder ao(s) documento(s) a partir de um endereço de IP da instituição detentora da supramencionada licença.

Ao utilizador é apenas permitido o descarregamento para uso pessoal, pelo que o emprego do(s) título(s) descarregado(s) para outro fim, designadamente comercial, carece de autorização do respetivo autor ou editor da obra.

Na medida em que todas as obras da UC Digitalis se encontram protegidas pelo Código do Direito de Autor e Direitos Conexos e demais legislação aplicável, toda a cópia, parcial ou total, deste documento, nos casos em que é legalmente admitida, deverá conter ou fazer-se acompanhar por este aviso.

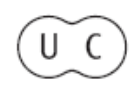




\section{Cadernos de}
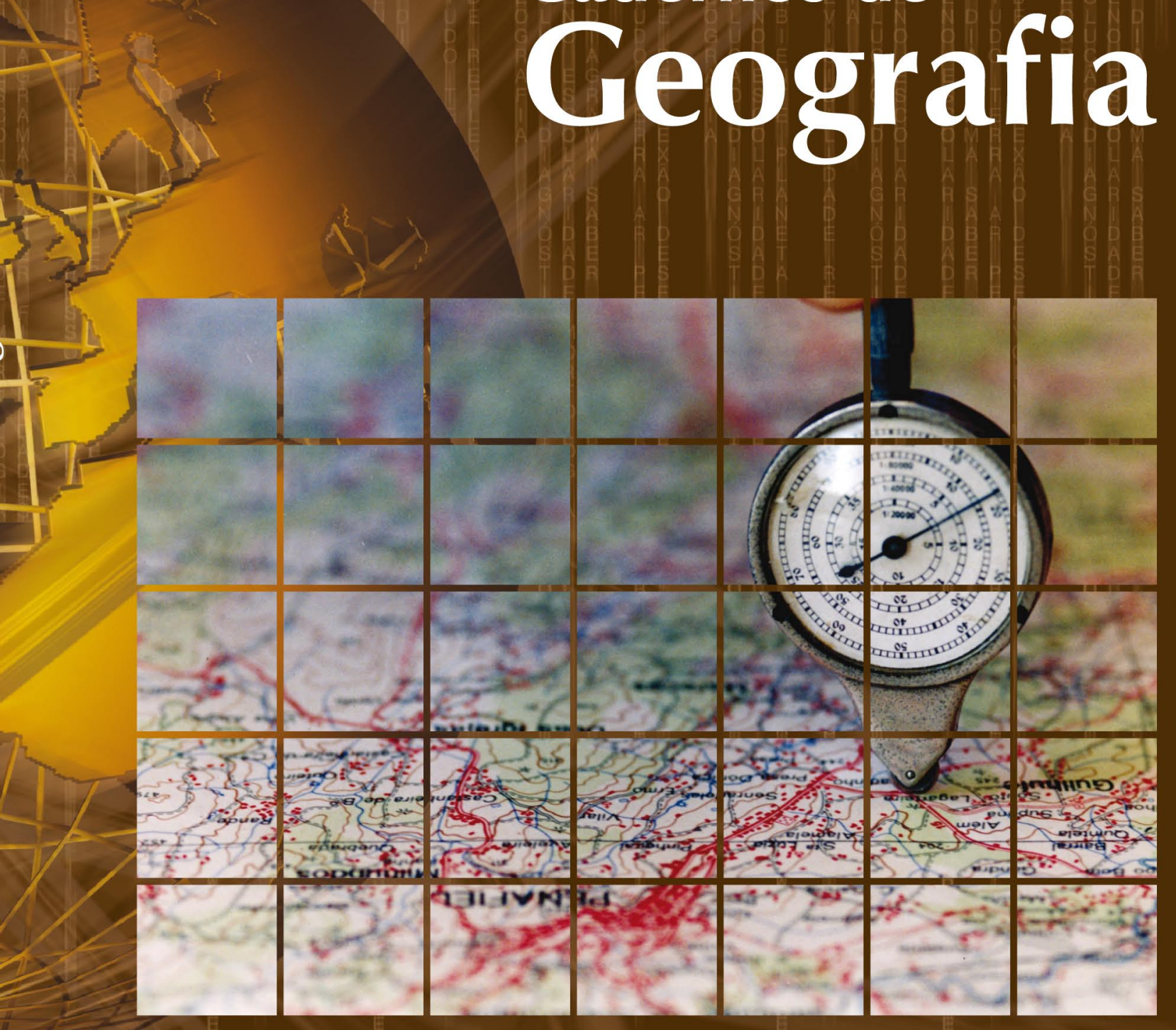

Imprensa da Universidade de Coimbra

Faculdade de Letras | Universidade de Coimbra 


\title{
Turismo na Serra da Estrela. Planeamento da atividade turística e desenvolvimento Tourism in Serra da Estrela. Planning of tourist activity and development
}

\author{
Carlos Costa \\ Centro de Estudos de Geografia e Ordenamento do Território - CEGOT. \\ cafcosta@portugalmail.pt
}

\section{Norberto Santos}

Departamento de Geografia e Turismo da Faculdade de Letras da Universidade de Coimbra e Centro de Estudos de Geografia e Ordenamento do Território- CEGOT. norgeo@ci.uc.pt

\section{Resumo:}

A atividade do turismo apresenta-se, hoje, por todo o mundo, como uma atividade em franco crescimento, capaz de gerar fluxos económicos significativos e novas oportunidades de desenvolvimento. Portugal e a região da Serra da Estrela, no contexto de uma economia aberta e globalizada, não se encontram à margem deste fenómeno.

Falar de turismo e de planeamento implica, forçosamente, falar de recursos, da sua gestão e do desenvolvimento económico que proporcionam a cada território. A maior ou menor atratividade que um destino turístico apresenta depende do modo como os recursos, qualitativamente representativos, se inter-relacionam. É nesta simbiose que a prática do planeamento em turismo assume a sua verdadeira importância nos termos da atual abordagem ao fenómeno turístico.

Nesse sentido, coloca-se em evidência o potencial turístico intrínseco à região da Serra da Estrela, designadamente a partir dos seus recursos mais atrativos, avaliando o impacto que o planeamento e uma correta gestão dos recursos turísticos podem ter no processo de transformação económica e social da região

Palavras-chave: Turismo de natureza. Recursos turísticos. Planeamento estratégico e sectorial. Gestão de destinos turísticos. Desenvolvimento turístico.

\section{Abstract:}

Nowadays, all over the world, the tourism activity presents itself as an activity which is growing rapidly, able to create significant economic flows and new development opportunities. Portugal and the region of Serra da Estrela, in the context of an open and globalised economy, aren't on the side lines of this phenomenon.

Discussing tourism and planning implies, inevitably, speaking of resources, their management and the economic development they provide to each territory. The higher or lower attractiveness a tourist destination presents depends on the way the resources, qualitatively representative, relate to each other. It is in this symbiosis that the practice of planning in tourism assumes its true importance under the present approach to tourism. The planning activity is strong and essential to a proper and proficient management of tourist destinations.

In this sense, it puts in evidence the tourist potential inherent to the Serra da Estrela region, namely from its most attractive features, evaluating the impact that the planning and proper management of tourism resources can have on the economic and social transformation of the region.

Keywords: Nature tourism. Tourist resources. Strategic and sectoral planning. Destination management. Tourism development.

\section{Introdução}

O turismo assume-se, presentemente, como um dos mais importantes setores de atividade económica à escala da economia mundial, em termos de criação de emprego, de crescimento económico, de valorização da imagem dos territórios, de obtenção de mais-valias sociais, patrimoniais, culturais, económicas e políticas, quando a gestão e o planeamen- to estruturam intervenções e formas de governança, de boas práticas e estratégia, no aproveitamento dos recursos de cada território.

Capazes de se transformarem em produtos competitivos por força do aproveitamento das suas vantagens comparativas e competitivas, os recursos endógenos e os exógenos de execução, intervenção e ação local/regional, assumem-se como elementos de apoio à sustentação do investimento produtivo. 
Este papel na socioeconomia releva-se, no caso português, ainda mais importante em regiões menos desenvolvidas do interior. A nível mundial, estima-se que o turismo de montanha seja responsável por quinze a vinte por cento do turismo (Moutain Agenda, 1999), se bem que estes sejam destinos de referência para o turismo de inverno e de neve, onde os elevados volumes de fluxos de pessoas e de capitais constituem a norma.

A região da Serra da Estrela apresenta especificidades próprias, obrigando a um enquadramento diverso. A quebra da atividade empresarial no último quartel do século passado, fortemente ancorada na atividade têxtil, contribuiu, de forma significativa, para o despovoamento dos territórios e desconexão das atividades do setor primário, com particular acuidade na atividade agrícola e da pastorícia, que se encontravam fortemente correlacionadas com este tipo de indústria. Este cenário pouco atrativo, caracterizado por um tecido económico empresarial fragilizado e movimentos demográficos de abandono da região, verificáveis, sobretudo, na última metade do século passado, ajudaram a que se olhasse para o turismo e para os recursos turísticos da região como âncora para o desenvolvimento. Cedo se percebe que a aposta num modelo de desenvolvimento não poderia ignorar o potencial da atividade turística, sendo a gestão do património existente (natural e cultural) o veículo para a preservação da diversidade das áreas rurais de baixa densidade e para um desenvolvimento territorial equilibrado, destas regiões deprimidas em recessão.

No sentido de compreender o conjunto intrincado de relações que se estabelecem entre a sociedade civil, a regulação política e o investimento económico, importa perceber o papel desempenhado pelas instituições que operam no terreno. Estas são responsáveis, em primeira instância, mas também no decurso dos processos, pela aplicação de políticas de ordenamento do território, pela gestão dos recursos ambientais e paisagísticos, pela promoção e operacionalização da atividade do turismo e, ainda, pela operacionalização de programas de financiamento ajustados à realidade do território em análise.

São vários os autores que têm defendido o alargamento do envolvimento de stakeholders no planeamento [participativo] e na gestão dos destinos e comunidades turísticas (Gartner, 1996; Williams, Penrose e Hawkes, 1998), ao reconhecerem os potenciais benefícios que a participação institucional pode trazer para as regiões de destino.

Assim, é propósito deste texto identificar as condições de logística, empresariais e institucionais, existentes na região, reconhecer e perceber os tipos de estratégias pensadas e adotadas pelas empresas a laborar no setor e diferentes stakeholders com interesse na atividade do turismo, propor uma orientação estratégica, de intervenções de âmbito turístico, que seja capaz de ser suporte para o desenvolvimento dos territórios, num destino de exceção, no contexto do turismo doméstico, a Serra da Estrela.

\section{Contextualização}

Num território fortemente disciplinado por planos de ordenamento do território, a diferentes escalas, como é o da Serra da Estrela, e pelo monopólio de exploração do turismo, a partir da cota dos $800 \mathrm{~m}$, pela TURISTRELA S.A., revelou-se de crucial importância perceber se o aproveitamento dos recursos existentes tem permitido produzir impactos visíveis sobre a socioeconomia, alcançando transformações ponderosas sobre o território em análise. Daqui resulta a principal questão a que se pretende dar resposta: quais as ações e intervenções que devem tomar lugar para a melhor gestão do destino turístico Serra da Estrela, no sentido da sustentabilidade territorial e do desenvolvimento?

Propõe-se a análise das opções de todos aqueles que possuem manifesto interesse no desenvolvimento da atividade do turismo, salvaguardando o superior interesse das comunidades autóctones, mormente no que concerne à sustentabilidade do território nas suas dimensões ambiental e paisagística.

A dimensão estratégica que se atribui à atividade do turismo, sobretudo em regiões de montanha e de baixa densidade, constitui o móbil para esta tentativa de entendimento do efeito motor que a atividade do turismo pode ter na socioeconomia deprimida da Serra da Estrela, outrora dinamizada pela indústria dos lanifícios e dos têxteis.

O pólo turístico da Serra da Estrela, em 2007, de acordo com o Plano Estratégico Nacional do Turismo (PENT - 2007), foi classificado como um dos seis pólos estratégicos a desenvolver, a par como o Alto Douro, o Oeste, o Alqueva, o Litoral Alentejano e Porto Santo, territórios que pelos seus conteúdos específicos e distintivos, justificaram uma gestão do poder central para a sua valorização no mercado nacional e no internacional.

A lógica de promoção externa do Turismo de Portugal para o Pólo foi a aposta nos mercados externos europeus, assumindo que este nunca será um turismo de massas. Também a investigação vai neste sentido, referindo a Serra da Estrela como mercado de nicho, para pessoas interessadas no turismo cultural, gastronómico ou de natureza, de acordo com Silva (2013).

Sempre que nos encontramos perante mercados de reduzida dimensão estamos, segundo Kotler (1996), perante um potencial nicho, ainda que a sua possível evolução em direção à constituição de um grande mercado seja uma realidade. 0 interesse pelos nichos de mercado não é algo novo. A novidade encontra-se no aumento da diversidade de mercados e no avanço das tecnologias que permitem novas abordagens de marketing. A aposta em nichos de mercado parece ser um método adequado a ser utilizado neste ambiente de mudança, à medida que se caminha para o alargamento dos espaços comuns, globalização de mercados e criação de um Euromarketing (Dalgic e Leeuw, 1994, apud Sousa e Simões, 2010: 141).

Hoje é evidente que existe uma aproximação entre as diferentes escalas de oferta turística. O turismo massificado organiza-se para modelos mais 
sustentáveis, sendo que o grande impacto reside no número de turistas (Krippendorf, 1987). Na verdade, o turismo de grande escala possui forças que podem ser utilizadas como vantagens. Clarke (1997) (Figura 1) refere: que o tamanho é importante porque os grandes players exercem maior pressão através do seu poder de lobbying contra outros setores que utilizam e afetam o ambiente; os grandes operadores têm competências de marketing e comunicação em rede, para ativamente estimular o interesse no turismo sustentável entre os seus clientes potenciais; a grande escala confere influência sobre fornecedores e distribuidores, que pode ser utilizado como força persuasiva para a introdução de políticas sustentáveis ao longo da cadeia de valor. O turismo sustentável é uma meta que todo o turismo tem que procurar, independentemente da escala (Inskeep, 1991). De facto, existe uma convergência (Clarke, 1997). O turismo associado a grandes empresas promove técnicas para induzir mudanças no comportamento turístico de forma a torná-lo compatível com a viagem ambientalmente amigável, uma componente educacional estimulada pelas empresas de pequena escala. Por outro lado, as pequenas empresas estão a integrar elementos sobre o desenvolvimento de sistemas de gestão ambiental eficazes, originalmente território de grandes organizações de turismo (Clarke, 1997).
Ainda assim, o turismo de nicho, ao contrário daquilo que se passa com o turismo massificado, apresenta-se como um tipo de turismo alternativo, dirigido para públicos distintos, segmentados, com um elevado nível de personalização. Este tipo de oferta permite sucessivos ajustamentos de molde a dar resposta a interesses especiais e enfatizar a autenticidade ou aos cenários autênticos, de acordo com Novelli (2005). O turismo de nicho encontra-se mais "associado a uma lógica de sustentabilidade territorial, de motivação e de escolhas turísticas alternativas, mais intimistas e genuínas, e também a novas modas, agregando uma miríade de produtos onde a escala limitada da procura tende a ser um dos critérios, ainda que subjetivos, de identificação" (Marques, 2013:28). Assumindo a convergência e a transversalidade da sustentabilidade, a problematização aqui expressa encontra-se orientada para a importância do turismo de escala pequena.

Reconhecendo-se a transversalidade da atividade do turismo revela-se essencial que este seja analisado sob um ponto de vista holístico, procurando-se «a essência total do assunto» (Beni, 2001: 36), dentro do seu próprio sistema e através das relações que cria com outros sistemas, como por exemplo, o económico, o social, o ambiental, o tecnológico, o institucional, o científico e académico.

\begin{tabular}{|c|c|}
\hline \multicolumn{2}{|c|}{ Turismo Sustentável } \\
\hline Turismo de Pequena Escala & Turismo de Grande Escala \\
\hline - Impactos globais & - Impactos globais \\
\hline - Impactos ecológicos & - Impactos socioculturais \\
\hline - $\quad$ Sistemas de gestão ambiental & - Integridade \\
\hline - Avaliação de impacto ambiental & - $\quad$ Autenticidade \\
\hline - $\quad$ Auditoria ambiental & Perfil dos visitantes \\
\hline - $\quad$ Reutilização, redução, reciclar & - $\quad$ Educação dos turistas \\
\hline - Orientação de sustentabilidade & - Orientação de sustentabilidade \\
\hline - $\quad$ Equididade & - $\quad$ Equididade \\
\hline - Foco nas empresas e organizações & - Local fator de identidade \\
\hline
\end{tabular}

Figura 1 Turismo Sustentável Adaptado de Clarke (1997: 230). 
Quando esteja em causa a determinação do potencial turístico de uma região, só através de uma avaliação rigorosa, que considere a oferta, a procura, a concorrência e as tendências do mercado, se alcançará o verdadeiro potencial de desenvolvimento turístico de um território (Zimmer e Grassmann, 1996).

Existem, fundamentalmente, dois tipos de turismo de montanha. O primeiro encontra-se vocacionado para a exploração de valores da natureza, conferindo-se particular importância às paisagens, à fauna, à flora, aos recursos hídricos e ao ar. Do ponto de vista da atividade do turismo, do recreio e do lazer, ganham importância atividades como o trekking, o pedestrianismo ou hiking, a escalada, o montanhismo, o rappel, o parapente, a canoagem e outras atividades que podem passar, inclusivamente, apenas por uma atitude contemplativa (paisagens) e/ou usufruto do ar e da água. Este tipo de turismo ocorre, sobretudo, quando a ausência da neve se faz sentir, tornando evidente o efeito da sazonalidade do turismo de inverno assente no recurso neve, típico de um clima com as características do da Serra da Estrela. 0 outro tipo de turismo de montanha ocorre quando a neve marca presença. Aqui, as principais atrações turísticas passam a ser as pistas de esqui e equipamentos de apoio. As baixas temperaturas associadas a paisagens sublimes com neve, em autênticos mantos brancos que se estendem sobre as montanhas, e a prática de diferentes modalidades de desporto de inverno atraem muitos turistas. É nesta simbiose que a oferta do turismo na Serra da Estrela deve ser perspetivada e analisadas as suas infraestruturas de apoio, para além, naturalmente, das estruturas administrativas de gestão e promoção do destino turístico. Recorde-se que o sucesso do destino reside na satisfação dos seus visitantes (Song et al., 2012: 460). Em suma, a complexidade das relações que envolvem a atividade do turismo e o território "tem modificado a perceção que se tem sobre esta atividade, devido à sua capacidade de gerar novos entornos com qualidade ambiental, (...) melhorar sua imagem e, assim, atrair novos investimentos e novos fluxos de turismo. Nesta perspetiva, o turismo deve ser visto como um fator de valorização do património natural e cultural" (Rebollo et al. 1997: 258) e, ainda, como atividade indutora de transformações sobre as sociedades e os territórios.

\section{Problemática e Objetivos}

O planeamento e a gestão da atividade do turismo na região da Serra da Estrela constituem o foco da problemática, alcançada através da identificação dos seus produtos turísticos, da definição de estratégias para valorização da oferta e do aproveitamento do seu potencial económico, constituída enquanto ferramenta de alavancagem para a consecução de um desenvolvimento efetivo a favor das populações das comunidades recetoras.

Os objetivos implícitos ao desenvolvimento de um estudo, conforme defende Perez (2001), traduzem- -se na componente mais importante da pesquisa, uma vez que o sucesso do estudo depende, em larga medida, da adequação dos objetivos ao problema e à realidade estudada, devendo, tanto os gerais como os específicos, ser claros, precisos e concisos e precisam adequar-se ao trabalho, o mais profusamente possível. Os objetivos devem deixar claro, também, o "campo de aplicação do estudo, tanto no espaço como no tempo, marcando a sua utilização" (Perez, 2001: 8).

Com o enquadramento do planeamento, da gestão dos destinos turísticos e do desenvolvimento de produtos turísticos associados ao território, propôs-se como objetivos: (i) identificar as características do território e competências organizativas capazes de permitir à atividade do turismo criar condições para a afirmação do turismo enquanto atividade de alavancagem económica e social numa região de montanha e de baixa densidade e (ii) determinar como o planeamento estratégico e uma correta gestão dos recursos influenciam o processo de transformação económica e social na Serra da Estrela, a partir da atividade do turismo.

Admitindo-se a hipótese de existência de uma variação concomitante e correlativa entre a atividade do turismo e o desenvolvimento, os objetivos gerais têm como finalidade colocar em evidência a necessidade de se compreender os efeitos relevantes da atividade do turismo no desenvolvimento social e económico das áreas de destino, quando sujeita a um planeamento eficaz.

De modo específico procura-se i) relacionar a atividade do planeamento com as transformações verificadas no território; ii) relacionar os investimentos efetuados com o volume de negócios da atividade turística e a criação de emprego; iii) comparar os resultados verificados na atividade do turismo com o tipo de gestão do destino (estruturas administrativas); iv) associar os fluxos de visitantes à valorização dos destinos pelo recurso ao marketing ${ }^{1}$.

\section{Enquadramento territorial}

Para o cidadão comum encontra-se já arreigada a ideia da divisão do país em regiões, sobretudo à escala das NUTS II. No entanto, o mesmo não sucede quando descemos na escala hierárquica, em direção à atual divisão sub-regional, correspondente às NUTS III, consolidada nas atuais Comunidades Intermunicipais (CIM). Raros são os cidadãos que reconhecem às sub-regiões NUTS III importância, enquanto unidades territoriais de referência a uma escala local, pela complexidade da sua génese, tempo de vigência e distanciamento da representatividade popular.

A nova unidade territorial, a CIM - Beiras e Serra da Estrela (CIMBSE), teve a sua génese com a

\footnotetext{
Teve-se, na definição destes objetivos, em linha de conta os pres supostos do estudo de Graburg em The Anthology of Tourism (1988) focado na variabilidade do turismo a partir dos fatores predominantes da sociedade de origem.
} 
publicação da Lei $n^{\circ}$ 75/2013, no dia 12 de setembro, em Diário da República. Esta unidade é o produto da fusão entre a Comunidade Intermunicipal da Serra da Estrela coincidente com a NUTS III Serra da Estrela, que integrava os concelhos de Seia, Gouveia e Fornos de Algodres, e da Comunidade Urbana das Beiras (Comurbeiras). Passou a abranger 15 municípios e integra três NUTS III - Beira Interior Norte, Cova da Beira e Serra da Estrela. Dela constam os concelhos de Almeida, Celorico da Beira, Figueira de Castelo Rodrigo, Guarda, Manteigas, Meda, Pinhel, Sabugal, Trancoso, Belmonte, Covilhã e Fundão, que faziam parte da CIM das Beiras, aos quais se juntaram os concelhos de Seia, Gouveia e Fornos de Algodres, que constituíam a CIM Serra da Estrela, esta última coincidente com a NUTS III Serra da estrela, como anteriormente se afirmou.

Os concelhos de Fornos de Algodres, Gouveia e de Seia, que anteriormente constituíam a NUTS III Serra da Estrela, constituem o território deste estudo.

De acordo com Valcárcel (2004: 7), “a montanha é um espaço construído socialmente, no qual as comunidades locais desenvolvem formas próprias de exploração dos recursos disponibilizados pela natureza, de forma sustentável, tendo em conta o contexto histórico, técnico, económico e social em que ocorrem". Reside, aqui, na essência desta abordagem, o ponto sobre o qual, definitivamente, importou colocar o enfoque deste estudo.

Esta região de elevado potencial turístico, para além da sua orografia vigorosa, oferece condições para a prática de diversos tipos de desportos de inverno, pela disponibilidade de neve ao longo de parte significativa do ano (Figura 2).

O território em análise fornece, igualmente, uma disponibilidade de recursos hídricos para a prática de desporto, recreio e lazer (figura $n^{\circ} 3$ ). As características físicas do território, consideradas singulares à escala regional e nacional, conferem-lhe vantagens inequívocas para o fomento da prática do turismo de natureza, enquanto alavanca para o desenvolvimento desta região.

O concelho de Seia, na qualidade de concelho mais dinâmico e competitivo em termos oferta de dormidas e receitas obtidas a partir da atividade do turismo, oferece um conjunto alargado de oportunidades aos visitantes. Uma das ofertas que foge, claramente, ao turismo de inverno e de neve, embora em contexto territorial de montanha, é aquela que é produzida pelas aldeias de montanha, sem olvidarmos os percursos pedestres das aldeias de

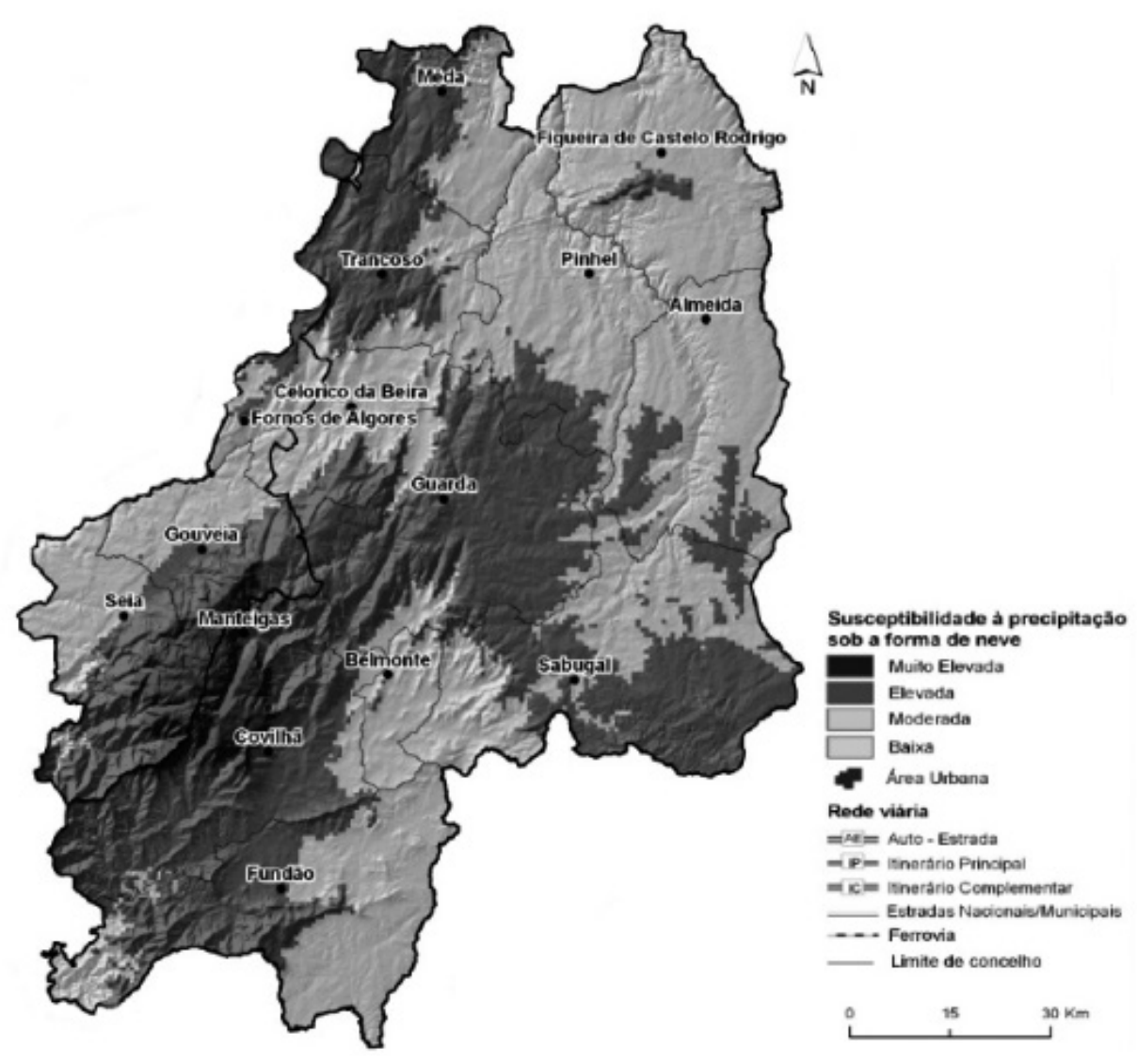

Figura 2

Carta sintética da suscetibilidade à precipitação sob a forma de neve, para a região da CIM Beiras e Serra da Estrela Fonte: Adaptado de CCDR Centro (2011) 


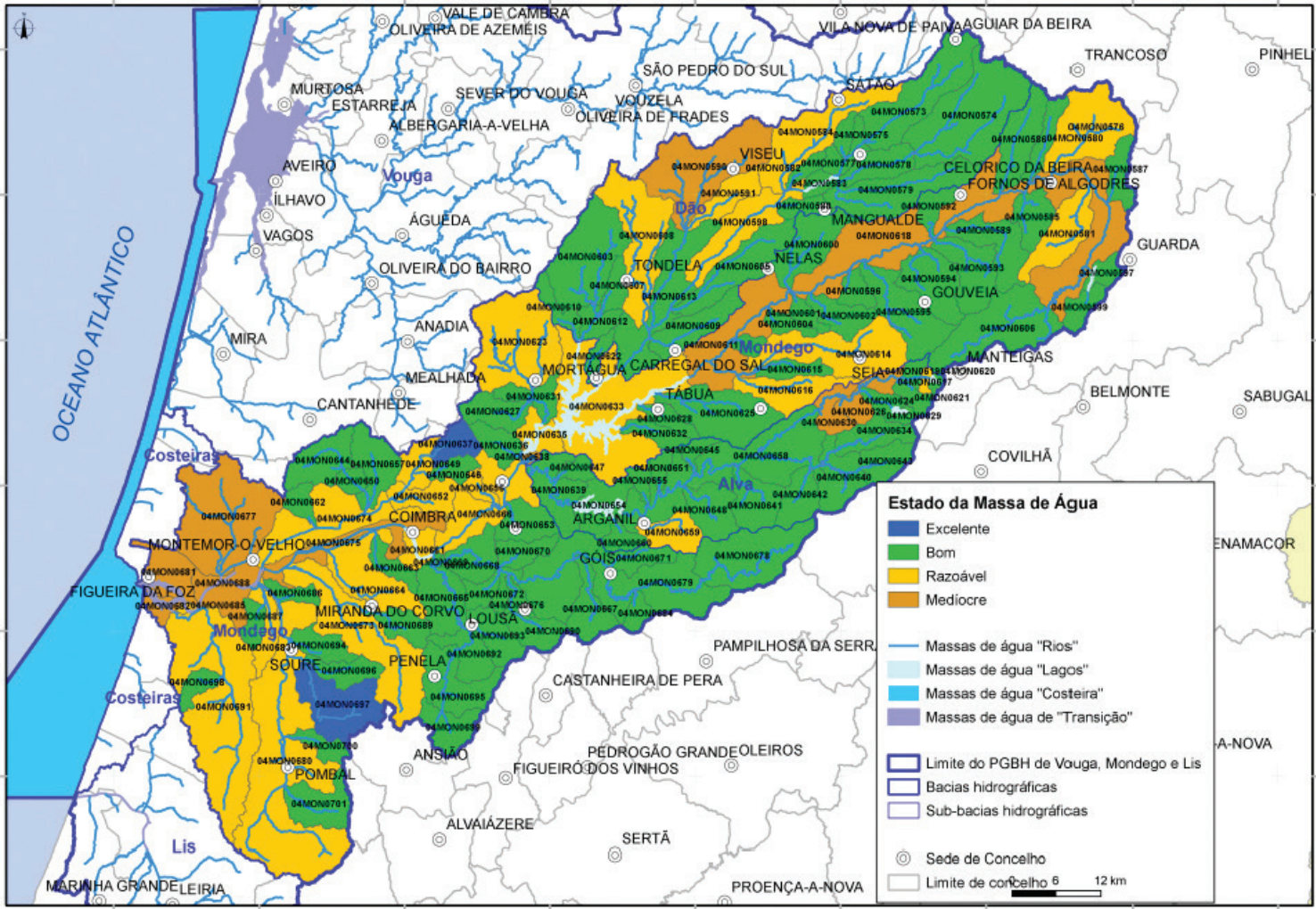

Figura 3

Massas de água no território em estudo (Fornos de Algodres, Gouveia e Seia)

Fonte: ARH Centro (2011)

montanha. Neste concelho, apesar do esforço evidenciado na oferta de infraestruturas de apoio à atividade turística (Museu do Brinquedo, Museu da Eletricidade, Museu do Pão, entre outros) é no Centro de Interpretação da Serra da Estrela (CISE) que encontramos o expoente máximo do património edificado com vocação para a promoção e divulgação do potencial ambiental e paisagístico da região. 0 concelho de Gouveia, por seu lado, tem feito um esforço significativo na divulgação da sua oferta começando, desde logo, pela apresentação do site do município onde o turismo ganha particular destaque, seja pelos equipamentos existentes ou eventos a realizar. Neste espaço é igualmente destacada a componente do turismo de natureza e cultural através da publicitação dos percursos pedestres e roteiro urbano. Quanto aos equipamentos, sem se esgotar o rol dos equipamentos disponíveis que possam encontrar-se correlacionados com a atividade do turismo, na sua vertente cultural, merecem destaque o Museu Abel Manta, o Museu da Miniatura Automóvel, o Espaço Arte e Memória, a Biblioteca Vergílio Ferreira, o Parque Ecológico, o Parque da Sr. ${ }^{a}$ dos Verdes e o Centro Hípico. Todos estes equipamentos são responsáveis por uma intensa atividade cultural, desportiva e recreativa, muitas delas com projeção mundial por integrarem os circuitos internacionais da(s) modalidade(s) promovida(s) ou por eventos mediáticos que aqui se ancoraram. Referência, ainda, para o Vale do Rossim, onde existe um projeto inovador, com forte aposta no turismo de camping, com um Ecoresort. Fornos de Algodres é, dos três conceIhos, aquele que oferece menos ações de apoio e disponibiliza menos equipamentos. Esta constatação pode ser feita, desde logo, através de uma consulta ao site da autarquia que se apresenta turisticamente pouco trabalhado. A Feira do Queijo é, do ponto de vista do turismo, a festa maior, sendo igualmente realizada nos outros concelhos aqui considerados. De realçar a praia fluvial de Fornos de Algodres - ponte de Juncais, que a par da praia fluvial de Loriga, da Senhora do Desterro e Vale do Rossim, do concelho de Seia e Gouveia, respetivamente, constituem atrações turísticas, em tempo de verão.

Espacialmente falando, considerando-se a CIMBSE, na sua totalidade, encontramo-nos perante um território que ocupa uma superfície de cerca de $6300 \mathrm{~km} 2$ e que, de acordo com os dados dos censos de 2011, possui 236.023 habitantes, caraterizado por um forte envelhecimento populacional. A extinta NUTS III - Serra da Estrela registou, neste mesmo recenseamento, 43.737 indivíduos residentes, distribuídos da seguinte forma: 4.989 no concelho de Fornos de Algodres; 14.046 em Gouveia e 24.702 no concelho de Seia, com uma densidade populacional de 50,0 hab/ Km2, valor, ainda assim, superior aos 
37,5 hab/Km2 da atual CIMBSE e inferior aos 82,3 hab/Km2 da Região Centro, valores próprios de territórios de baixa densidade.

\section{Metodologia de investigação.}

Para a compreensão das relações existentes entre os diferentes constructos da investigação, revelou-se importante proceder à organização de um mapa concetual, de modo a permitir estruturar eficazmente o processo evolutivo da investigação e, sobretudo, como ferramenta de avaliação (Mintzes et al., 2000; Novak, 1990; Novak; Gowin, 1984).

O mapa concetual que aqui se apresenta não resulta de um conjunto de conceitos, mas é, antes, o produto da reflexão da análise efetuada, partindo do pressuposto de que os mapas concetuais são sempre diferenciados na sua elaboração e na sua interpretação (Novak, 1981).

A ideia de utilizar mapas mentais como forma de agilizar o processo de investigação obtendo e representando os requisitos é defendida por muitos autores (Ambler, 2002; Larman, 2003) e permitiu a organização do modelo concetual da figura $n^{\circ} 4$. Como oportunamente se referiu, o turismo é um fenómeno que movimenta milhões de pessoas em todo o mundo, apresentando-se como um dos mais importantes motores da economia a diferentes escalas. Verifica-se, face às frequentes alterações no ambiente da atividade do turismo, que a com- petição é fomentada entre e no próprio contexto dos destinos turísticos (Farhangmehr e Simões, 1999), conferindo-lhe um caráter cada vez mais multifacetado e geograficamente complexo, onde diferentes serviços são solicitados e fornecidos em diferentes estágios, desde a origem até ao destino (Pearce, 1998).

Conscientes de que para se construir um produto ou sistema com um fim específico é necessário desenvolver um modelo concetual ajustado às necessidades (Fowler, 1997) importa, de acordo com as características da matéria em análise, partilhar o correspondente modelo concetual.

O modelo concetual exposto representa uma perspetiva global sobre a questão em análise, colocando em evidência três grupos de constructos que estabelecem, significante relação entre si, a saber: fatores antecedentes do comportamento espácio-temporal: internos e externos; ação do planeamento: i) com incidência sobre o território na sua vertente física e ambiental; ii) de incidência estratégica nas dimensões económica, social e ambiental; transformações recentes, traduzidas em alterações dos padrões da oferta, tipo de turistas, permanência e consumo.

No que concerne ao planeamento, para além da necessidade da sua aplicação para efeitos de correção dos desequilíbrios à escala local e regional, importa projetá-lo para a sua dimensão estratégica, com aplicação à atividade do turismo. De acordo com Rebollo (1996), o território assume capital importân-

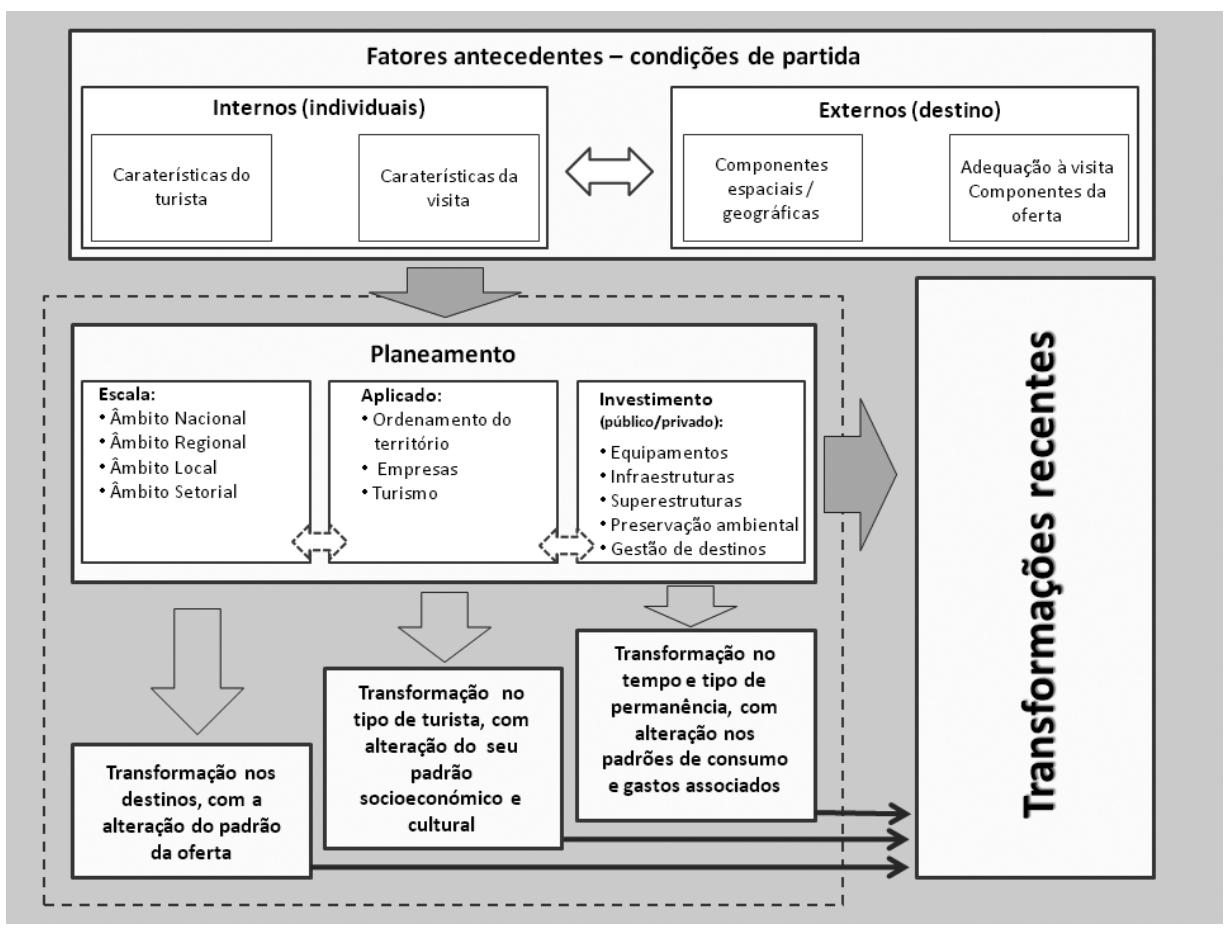

Figura 4

Modelo conceptual da investigação

Fonte: Elaboração própria 
cia no processo de transformação das vantagens comparativas em vantagens competitivas, pela flexibilidade da oferta e no uso racional dos recursos. Apesar do fenómeno multiatrações estabelecer uma relação com os territórios urbanos, o facto é que conforme refere Mason (2003), o planeamento pode ser implementado em diferentes contextos geográficos (urbano e rural), assim como ser aplicado em diversas escalas (local, regional e nacional). É justamente, aqui, que se encontra o cerne da questão.

A necessidade de se aplicar o planeamento aos destinos turísticos, do ponto de vista de uma ação de marketing, poderá concorrer de forma decisiva para a criação de novos produtos ajustados às necessidades de um mercado concreto. Esta prática permite uma diferenciação face aos destinos concorrentes, criando condições objetivas para que o sucesso no mercado seja efetivo (Kastenholz, et al., 1999). O estudo do planeamento de um destino turístico é quase que indissociável do estudo do comportamento da procura e do consumidor. Swarbrooke e Horner (1999) destacaram-se, neste particular, incidindo a sua análise em torno do processo de decisão de compra do consumidor (determinantes, motivações e modelos do processo de tomada de decisão) assim como na sistematização de diversas tipologias do comportamento turístico e segmentação do mercado.

Foram diversos os autores que prestaram um importante contributo em matéria de análises metodológicas do planeamento turístico, reportando aos modelos de espaço turístico (Callizo, 1991 e Pearce, 2003), modelos de viagem turística (Dredge, 1999), modelos estruturais (Pearce, 1995 e Dredge, 1999) e (Dredge, 1999) e modelos de evolução.

Do ponto de vista metodológico adotou-se o método Delphi, que consiste numa técnica que apresenta como principal objetivo filtrar a opinião de especialistas convidados, respeitando toda uma gama de procedimentos rigorosos. É usado, sobretudo, para alcançar consensos de opinião, julgamento ou escolha, designadamente para determinar, prever e explorar atitudes de grupos, estabelecer necessidades e definir prioridades.

Face à importância que a constituição do painel de especialistas convidados assume para um desempenho eficaz da técnica Delphi, dedicou-se especial atenção à seleção dos seus elementos, le- vando-se em consideração as sugestões mais pertinentes, apontadas pela literatura de referência. Assim, destacamos a consulta a autores com publicações e artigos sobre a técnica Delphi, o contacto prévio com individualidades de reconhecido mérito, com experiencia relevante na atividade do turismo, e o contacto realizado com instituições com interesses no setor.

No processo de seleção foram tidos em consideração vários critérios, designadamente o local de residência, o grau académico e a experiência profissional de cada especialista convidado. Valorizada a experiência profissional individual, considerando-se como relevante o conhecimento do tema em estudo, a capacidade de produção de debates, ideias e opiniões, foram selecionados 5 grupos, como indicado no Quadro I, com plena participação nas três rondas.

Quadro

Número de participantes em cada ronda e respetiva distribuição tendo em conta a sua experiência profissional.

\begin{tabular}{|l|c|c|c|}
\hline & $\begin{array}{c}1^{\mathrm{a}} \\
\text { Ronda }\end{array}$ & $\begin{array}{c}2^{\mathrm{a}} \\
\text { Ronda }\end{array}$ & $\begin{array}{c}3^{\mathrm{a}} \\
\text { Ronda }\end{array}$ \\
\hline Empresários ligados ao setor & 5 & 5 & 5 \\
\hline $\begin{array}{l}\text { Dirigentes e Técnicos Cooperativos/ } \\
\text { Associativos }\end{array}$ & 4 & 4 & 4 \\
\hline Entidades Governamentais & 4 & 4 & 4 \\
\hline $\begin{array}{l}\text { Académicos (Professores do Ensino } \\
\text { Superior Universitário)z }\end{array}$ & 4 & 4 & 4 \\
\hline Técnicos Superiores do Poder Local & 4 & 4 & 4 \\
\hline Total & 21 & 21 & 21 \\
\hline
\end{tabular}

Fonte: Elaboração própria

No que concerne à habilitação académica, idade, residência e sexo, os especialistas convidados apresentam a seguinte estrutura (Quadro II) em termos de distribuição, considerando-se, para contabilização da idade, o ano em que ocorreu a primeira ronda do inquérito:

Segundo Adler e Ziglio (1996), o método Delphi sustenta-se num processo estruturado, capaz de recolher e sintetizar os conhecimentos de um grupo de especialistas convidados, através de uma série de questionários capazes de fornecer uma retroação organizada de opiniões. Estes questionários, que são objeto de várias rondas de inquirição, permitem que seja obtido um consenso através de um processo de

Quadro II

Caracterização dos participantes e respetiva distribuição em função da escolaridade, idade, residência e sexo.

\begin{tabular}{|c|c|c|c|c|c|c|}
\hline Habilitações & E. Secundário & Licenciatura & Bacharelato & Mestrado & Doutoramento & Total \\
\hline & 1 & 12 & 1 & 4 & 3 & 21 \\
\hline Idade & $25-30$ & $31-40$ & $41-50$ & $51-60$ & $>60$ & \\
\hline & 0 & 1 & 9 & 6 & 5 & 21 \\
\hline Residência & NUT III - SE & Distrito - Guarda & Região Centro & Continente & & \\
\hline & 13 & 2 & 5 & 1 & & 21 \\
\hline Sexo & Masculino & Feminino & & & & 21 \\
\hline & 14 & 7 & & & & \\
\hline
\end{tabular}

Fonte: Elaboração própria 
convergência de respostas, representando a consolidação do julgamento intuitivo do grupo, segundo Wright e Giovinazzo (2000). Os especialistas convidados prestam, assim, um importante contributo ao processo de investigação ao disponibilizarem os seus conhecimentos, a par das experiências individuais armazenadas ao longo das suas vidas, no que concerne aos processos de tomada de decisão, em domínios tão importantes como o do planeamento e da gestão, nomeadamente naqueles que dizem respeito à gestão dos destinos turísticos.

O método Delphi revela-se útil quando se pretende levar a efeito uma análise qualitativa, autorizando a projeção de tendências para o futuro, face a intermitências da componente tecnológica e alterações socioeconómicas. 0 método sustenta-se numa técnica que se reveste de alguma simplicidade, consistindo no envio de um conjunto de questionários a um grupo pré-selecionado de especialistas convidados.

O método Delphi consiste num processo estruturado capaz de obter um «consenso mais fiável de opinião de um grupo de peritos com base numa série de questionários intensivos intercalados com o feedback de pareceres controlado» (Helmer, 1983: 135) que passa pela obtenção de respostas individualizadas para uma questão específica, que vão sendo aperfeiçoadas à medida que o trabalho evolui com a confrontação dos resultados alcançados em cada ronda. Apresenta-se «como um método para estruturar o processo de comunicação em grupo desde que esse processo seja efetivo em permitir um grupo e indivíduos, como um todo, partilhar um problema complexo" (Linstone e Turoff, 2002: 3). Nesse sentido, foram organizadas as seguintes hipóteses de trabalho:

H1 Existe a prevalência dos recursos naturais sobre os culturais e construídos na determinação das vantagens comparativas para a afirmação do turismo na região da Serra da Estrela;

H2 A sazonalidade é característica condicionante do turismo na região da Serra da Estrela;

H3 Os fluxos turísticos são condicionados pela acessibilidade

H4 A marca "Serra da Estrela" é fundamental para a escolha da região como destino turístico e para a valorização do marketing turístico;

H5 As estruturas administrativas de gestão dos destinos turísticos são imprescindíveis para a afirmação do destino "Serra da Estrela";

H6 A elaboração de planos sectoriais de intervenção, para a atividade do turismo, revela-se fundamental para o sucesso do turismo.

\section{Análise dos resultados}

Sustentados na análise das limitações verificadas no decurso da investigação, que fundamentam a pertinência da pesquisa, avança-se com uma síntese analítica dos principais resultados empíricos e a avaliação do modelo proposto. Assim, nesta reflexão considera-se não só a importância que um planea- mento sustentável assume no âmbito da atividade turística (Hall, 2000; Krippendorf, 1989 e Mathieson e Wall, 1982) mas, sobretudo, a importância que a atividade turística assume no processo de transformação das sociedades, das pessoas e dos territórios nos lugares de destino.

No que concerne à testagem das hipóteses, alcançaram-se as seguintes conclusões: hipótese 1 o coeficiente de concordância (W de Kendall ${ }^{2}$, $0,905)$, verificado na $3^{a}$ ronda, no que respeita à aposta no Turismo da Natureza e no Turismo Aventura, ficou muito próximo da concordância plena, facto que valida o postulado da hipótese: "Existe prevalência dos recursos naturais sobre os culturais e construídos na determinação das vantagens comparativas para a afirmação do turismo na região da Serra da Estrela"; hipótese 2 - $\mathrm{Na} 3^{\mathrm{a}}$ ronda solicitou-se uma apreciação às três justificações mais significativas, que foram avançadas pelo painel na $2^{\text {a }}$ ronda, sobre a sazonalidade, onde $95,2 \%$ concordaram (muito e plenamente) que o fator sazonalidade do recurso natural neve funciona como elemento explicativo para a necessidade de se procurarem outras alternativas. Verificou-se um coeficiente de concordância de 0,706 para o alinhamento de respostas facultadas pelo painel. Estes valores permitem validar o postulado de que "A sazonalidade é característica condicionante do turismo na região da Serra da Estrela"; hipótese 3 - Apesar do painel de especialistas ter englobado, num primeiro momento, a dimensão acessibilidades no conjunto de infraestruturas mais deficitárias de apoio à atividade do turismo na região, depois de analisados os resultados da $1^{\text {a }}$ ronda, quando se propôs, já no âmbito da $2^{\mathrm{a}}$ ronda, um leque alargado de propostas formuladas pelo próprio painel de especialistas convidados para que fossem indicadas as apostas prioritárias em infraestruturas na região, a partir do lote das mais deficitárias por eles indicadas, verificou-se uma alteração na forma como a questão das acessibilidades passou a ser perspetivada, perdendo a importância que inicialmente the tinha sido reconhecida. Ao quedar-se num modesto sexto lugar, em termos de aposta prioritária (consideravam-se, apenas, as três primeiras prioridades) a desenvolver em termos de infraestruturas para a região, materializado num coeficiente de concordância (W de Kendall) de 0,458 para o ordenamento do conjunto de respostas avançado pelo painel, o valor alcançado, não permitiu a validação da hipótese 3: “Os fluxos turísticos são condicionados pela acessibilidade"; hipótese 4 - Constatou-se, da análise às respostas facultadas pelos membros do painel, que a concentração dos recursos identitários da Serra da Estrela se verifica, sobretudo, no contexto dos

\footnotetext{
Para se proceder à avaliação de vários conjuntos de posições (escala de postos) dos mesmos indivíduos, cujas variáveis são medidas em escala ordinal foi usado o coeficiente de concordância de Kendall (W de Kendall). Numa avaliação dos pares de concordância se a HO se confirmar (não há concordância entre os avaliadores) o coeficiente de concordância de Kendall é igual a zero (W de Kendall $=0$ ) se, pelo contrário, se confirma a $\mathrm{H} 1$ (há concordância entre os avaliadores), o coeficiente de concordância de Kendall é igual a 1 (W de Kendall $\neq 0$ ), sendo o nível de significância de 0,05.
} 
recursos naturais. Os resultados de coeficiente de concordância obtidos validaram as respostas facultadas pelos especialistas convidados para todos os concelhos, obtendo-se 0, 544 para Fornos de Algodres, 0,659 para Gouveia e 0,702 para Seia. Tendo em vista a determinação da importância destes recursos para a afirmação do turismo procedeu-se a igual testagem, a partir do coeficiente de concordância das respostas obtidas e alcançou-se o resultado global (W de Kendall) de 0,532, o que valida o alinhamento das respostas facultadas pelo painel, conferindo aos recursos identitários da imagem "Serra da Estrela" potencial atrativo e de afirmação do turismo, de acordo com o postulado da hipótese “A marca Serra da Estrela é fundamental para a escolha da região como destino turístico e para a valorização do marketing turístico"; hipótese 5 Depois de na $1^{\text {a }}$ ronda terem sido avançadas as diferentes propostas de tipo de estrutura administrativa a integrar, tendo em vista a valorização do turismo na região da Serra da Estrela, na $2^{a}$ ronda solicitou-se a escolha de uma das duas modalidades que mereceram maior referência (Tourism Think Tank, Destination Marketing Organization) ou, eventualmente, nenhuma delas. A aposta do painel foi para o TTT, onde foi igualmente expressa a sequência de ações a desenvolver pela estrutura depois de implementada. Do alinhamento das respostas resultou um coeficiente de concordância de 0,653, valor que permitiu a validação da hipótese “As estruturas administrativas de gestão dos destinos turísticos são imprescindíveis para a afirmação do destino Serra da Estrela"; finalmente a hipótese 6 - Perguntou-se ao painel, na $1^{\text {a }}$ ronda, se concordava que a elaboração de planos sectoriais para a atividade do turismo, independentemente da sua área geográfica de intervenção, se revelava fundamental para o sucesso da atividade turística. Obtiveram-se $86 \%$ de respostas concordantes, logo na primeira abordagem. $\mathrm{Na} 2^{\mathrm{a}}$ ronda solicitou-se aos membros do painel que indicassem o seu nível de concordância com as fundamentações apresentadas na $1^{\text {a }}$ ronda, tendo sido apontada por $95 \%$ dos membros (concordo muito e concordo plenamente) a justificação de que: “é o planeamento que conduz à definição de estratégias de intervenção nos territórios". Do alinhamento das respostas, relativamente às fundamentações apresentadas na $1^{\text {a }}$ ronda, resultou um índice de concordância (W de Kendall) de 0,532 para a primeira opção. Explorando a importância do planeamento setorial, ajustado à realidade territorial, os especialistas convidados entenderam, caso o PETUR tivesse sido implementado, que se poderia ter constituído como base de sustentação para a melhoria dos resultados da atividade do turismo na região da Serra da Estrela, 55\% declaram algum tipo de melhoria, desde pouca melhoria $(10 \%)$, melhoria razoável $(20 \%)$ e melhoria significativa $(25 \%)$. Na $2^{\text {a }}$ ronda foram $71 \%$ os membros do painel que entenderam que; "este plano apontava para novas formas de turismo, onde as autarquias, conjuntamente, desenvolveriam uma estratégia comum de melhoria de oferta turística".
Do alinhamento das respostas resultou o coeficiente de concordância (W de Kendall) de 0,563. Finalmente, quando na $3^{\text {a }}$ ronda se perguntou se "estavam de acordo quanto ao aproveitamento das ideias constantes no PETUR para a resolução dos problemas do turismo na região da Serra da Estrela, a realizar pelos municípios a título individual", 52\% dos membros do painel concordaram com essa possibilidade, reconhecendo, implicitamente, a mais-valia do plano, enquanto plano ajustado ao setor. Posto o alinhamento das provas estatísticas confirma-se a hipótese de que "A elaboração de planos sectoriais de intervenção para a atividade do turismo se revela fundamental para o sucesso do turismo"

\section{Considerações finais}

No que respeita às implicações para o território em estudo, constata-se que os recursos naturais existentes assumem particular preponderância na definição da tipologia de turismo a desenvolver e tipo de turista a valorizar. Os recursos naturais têm funcionado como o motor da atividade turística ao constituírem-se, na sua maior parte, como atrações turísticas.

No que respeita à sazonalidade, pode afirmar-se que esta se apresenta como uma das mais importantes características do turismo português (Baum e Lundtorp, 2001), em termos gerais, e muito particularmente na região da Serra da Estrela, que é o território que aqui nos interessa realçar. Se na globalidade do território português o efeito da sazonalidade se caracteriza pela procura verificada nos meses mais quentes do ano, na região da Serra da Estrela passa-se, precisamente, o inverso, desenvolvendo-se um esforço em termos de diversificação da oferta, na região da Serra da Estrela, cujo principal objetivo visa a diminuição da dependência do turismo de neve.

Relativamente à imagem de marca "Serra da Estrela", enquanto elemento fundamental para a escolha da região como destino e valorização do marketing turístico, convém reter, antes de tudo, que de um ponto de vista estritamente estratégico a gestão do marketing dedica especial cuidado à imagem de marca dos produtos e no efeito que eles provocam no mercado, sendo certo que influenciam, em diferentes graus, a decisão final dos consumidores. Assim, a apresentação de uma imagem de marca forte e consolidada no mercado em que o destino turístico concorre configura-se como garantia acrescida de prosperidade (Fakeye e Crompton, 1991) e, ao mesmo tempo, uma forma acrescida de influenciar o comportamento consumista dos turistas (Ashworth e Goodall, 1988; Bignéet al., 2001; Mansfeld, 1992), algo que persegue pelo reconhecimento da sua importância.

Relativamente às estruturas administrativas de gestão dos destinos turísticos importa, em primeira instância, proceder ao enquadramento dos seus objetivos e conteúdos funcionais. O TTT, que foi valorizado pelos especialistas convidados, passa, 
antes de tudo, por se constituir como uma organização capaz de gerir os interesses de um destino, coordenando as contribuições prestadas por diferentes tipos de participantes com diferentes níveis de especialização e diferentes conteúdos profissionais, embora todos interligados pela mesma atividade e pelos mesmos interesses, ao serviço da resolução de problemas complexos para o sucesso do Turismo de um modo abrangente. Esta estrutura consubstancia-se num processo de partilha sob o princípio de Give and Get, de modo a dar resposta às diferentes necessidades do turismo. Quando implementado e, sobretudo, se bem-sucedido, torna-se como um elemento de referência, independentemente do seu contexto físico, onde as comunidades com interesses comuns se encontram para partilhar insights, conhecimento e melhores práticas. Aqui não se trata, apenas, de problemas diretamente relacionados com o turismo, mas, igualmente, de questões relacionadas com a mobilidade social e económica que têm grande impacto sobre o meio ambiente, economia e estruturas sociais (Gössling, Williams e Dubois, 2012), algo a que os especialistas convidados foram muito sensíveis.

Finalmente, no que concerne à elaboração de planos sectoriais de intervenção para a atividade do turismo, a sua materialização revela-se fundamental para o sucesso do turismo. Ele deve assumir-se, para além de estratégico, integrador, participativo e pluralista, no sentido de envolver as dimensões sociais, económicas e físicas, porque na ausência de planeamento estratégico as organizações tendem a decidir casuisticamente e de forma reativa (Tribe, 2005).

O turismo, como tivemos oportunidade de constatar, pode constituir-se como uma alavanca para o desenvolvimento local em territórios de baixa densidade e de montanha. O setor do turismo, por se encontrar em plena expansão, permite dinamizar as atividades económicas tradicionais e valorizar, ao mesmo tempo, as especificidades culturais locais, propiciando novas oportunidades para estas zonas, designadamente em matéria de emprego para jovens, contribuindo para que se trave, simultaneamente, o êxodo rural.

\section{Bibliografia}

Adler, M., \& Ziglio, E. (1996). Gazing into the oracle: the Delphi method and its application to social policy and public health. London: Jessica Kingsley Publishers.

Ambler, S. (2002). Agile modeling: effective practices for extreme programming and the unified process. New York: John Wiley \& Sons, Inc.

Ashworth, G. \& Goodall, B. (1988). Tourist images: marketing considerations, marketing in the tourism industry - the promotion of destination regions. In B. Goodall, \& G. Ashworth (Edits.). UK: Routhlegde.
Baum, T. \& Lundtorp, S. (2001). Seasonality in tourism. Oxford: Pergamon.

Beni, M. (2001). Análise estrutural do turismo ( $6^{\mathrm{a}}$ ed. $)$. S. Paulo: SENAC.

Bigné, E.; Sánchez, M. \& Sánchez, J. (2001). Tourism image, evaluation variables and after purchase behaviour: inter-relationship. Tourism Management, 22, 607-616.

Callizo, J. S. (1991). Aproximación a la Geografia del Turismo. Madrid: Síntese.

Clarke, Jackie (1997). A framework of approaches to sustainable tourism. Journal of Sustainable Tourism, 5(3), 224-233,

Dredge, D. (1999). Destination place planning and design. Annals of Tourism Research, vol. 26, n 4, 772-791.

Fakeye, P. \& Crompton, J. (1991). Image differences between prospective, first-time and repeat visitors to the lower Rio Grande valley. Journal of Travel Research, 30(2), 10-16.

Farhangmehr, M. \& Simões, C. (1999). Factors affecting hotel industry development in Portugal. Journal of Hospitality Marketing \& Management, 6(1), 23-46.

Fowler, M. (1997). Analysis patterns, reusable object models. Addison Wesley.

Gartner, W. (1996). Tourism development: principles, processes and policies. New York: Van Nostrand Reinhold.

Gössling, S.; Williams, A. \& Dubois, G. (2012). BEST education network think tank. Ecotourism and Sustainable Tourism Conference.

Hall, M. (2000). Tourism planning. Policies, processes and relationships. Harlow: Prentice Hall.

Helmer, O. (1983). Looking forward. A guide to futures research. Beverly Hills: Sage Publ.

Inskeep, E. (1991). Tourism planning: an integrated and sustainable development Approach. New York: Van Nostrand Reinhold.

Kastenholz, E.; Davis, D. \& Paul, G. (1999). Segmenting tourism in rural areas: the case of north and central Portugal. Journal of Travel Research, 37(4), 353-363.

Kotler, P. (1996). Administração de marketing. 4. ed. São Paulo: Atlas.

Krippendorf, J. (1989). Sociologia do turismo. Para uma nova compreensão do lazer e das viagens. Rio de Janeiro: Civilização Brasileira.

Linstone, H. A. \& Turoff, M. (2002). The Delphi method: Techniques and applications. New Jersey: Departement of Information Systems, New Jersey's Science \& Technology University.

Mansfeld, Y. (1992). From motivation to actual marketing. Annals of Tourism Research, 19, 399-419. 
Marques, J. H. (2013). Turismo de negócios. Convention \& visitors bureau na Região Centro. Tese de Doutoramento não publicada. Coimbra: Universidade de Coimbra.

Mason, P. (2003). Tourism impacts, planning and management. London: Butterworth- Heinemann.

MAOT - Ministério do Ambiente e Ordenamento do Território (2011). Plano de Gestão das Bacias Hidrográficas dos rios Vouga, Mondego e Lis, s.l., ARHC - Administração da Região Hidrográfica do Centro, IP.

Mathieson, A. \& Wall, G. (1982). Tourism: economic, physical and social impacts. Essex: Longman Scientific \&Technical.

MEI - Ministério da Economia e da Inovação (2007). Plano estratégico nacional do turismo. Lisboa: Turismo de Portugal, IP.

Mintzes, J. J.; Wandersee, J. H., \& Novak, J. D. (2000). Assessing science understanding: a human constructivist view. San Diego: Academic Press.

Mountain Agenda (1999). Mountains of the world: tourism and sustainable mountain development. Institute of Geography, University of Berne, Switzerland.

Novak, J. D. (1981). Uma teoria da educação. Trad. de M. A. Moreira. São Paulo: Pioneia.

Novak, J. D. (1990). Concept maps and vee diagrams: two metacognitive tools for science and mathematics education. Instructional Science, vol. 19, 29-52.

Novak, J. D. \& Gowin, D. B. (1984). Learning how to learn. New York: Cambridge University Press.

Novelli, M. (2005). Niche tourism contemporary issues trends and cases. Oxford: Elsevier.
Pearce, D. G. (1998). Tourism development in Paris: public intervention. Annals of Tourism Research, vol. 25, 457-476.

Pearce, D. G. (2003). Geografia do Turismo. Fluxos e regiões no mercado de viagens. Trad. S. Krieger. São Paulo: Aleph.

Perez, A. S. (2001). Apuntes de metodologia de la investigaciónen Turismo. Madrid: OMT.

Rebollo, V. (1996). Análisis territorial del turismo. Barcelona: Ariel.

Rebollo, V. (1997). Análisis territorial del turismo. Una nueva Geografía del Turismo. Barcelona: Ariel, Col. Geografia.

Sousa, B. \& Simões, C. (2010). Comportamento e perfil do consumidor de turismo de nichos. Revista de Estudos Politécnicos, vol. VIII, n 14, 137-146.

Swarbrooke, J. \& Horner, S. (1999). Consumer behavior in tourism. Butterworth-Heinemann.

Tribe, J. (2005). The economics of tourism destinations ( $3^{\text {a }}$ ed.).Oxford: Elsevier.

Valcárcel, J. (2004). Áreas de montaña: de la supervivencia a la integración. Boletin de la A.G.E., $\mathrm{n}^{\circ}$ 38, 5-28.

Williams, P.; Penrose, R. \& Hawkes, S. (1998). Shared decision-making in tourism land use planning. Annals of Tourism Research, v.25, $n^{\circ} 4,860-889$.

Zimmer, P. \& Grassmann, S. (10-13 de Janeiro de 1996). Avaliar o potencial turístico de um território. LEADER II.

Texto recebido em/Text submitted on: $31 / 03 / 2016$ Texto aprovado em/Text approved on: 22/07/2016 